\title{
Sirius and the project of the megalithic enclosures at Gobekli Tepe
}

\author{
Giulio Magli ${ }^{1}$
}

Published online: 23 November 2015

(C) Kim Williams Books, Turin 2015

\begin{abstract}
The megalithic enclosures of Gobekli Tepe (Urfa, Turkey) are the most ancient stonebuilt sacred structures known so far, dating back to the 10th millennium BC. The possible presence of astronomical targets for these structures is analysed, and it turns out that they may have been oriented-or even originally constructed - to celebrate and successively follow the appearance of a new, extremely brilliant star in the southern skies: Sirius.
\end{abstract}

Keywords Göbekli Tepe $\cdot$ Archaeoastronomy $\cdot$ Megalithic sites $\cdot$ Sirius alignments

\section{Introduction}

Göbekli Tepe, a hill in the province of Urfa in south-eastern Turkey $\left(37^{\circ} 13^{\prime} 25^{\prime \prime} \mathrm{N}\right.$, $38^{\circ} 55^{\prime} 34^{\prime \prime} \mathrm{E}$, altitude $779 \mathrm{~m}$.) is the place of the first "temples" that we are aware of (Schmidt 1998, 2001, 2006, 2010). The hill is in fact covered by a series of circular and rectangular enclosures, of which only a few have been excavated to date (Fig. 1).

Archaeologically, the history of the site is quite neatly divided. The oldest layer, Layer III, contains circular wall precincts in which several T-shaped monolithic pillars, generally finely engraved, are nested. Two further pillars stand in the centre of each enclosure, parallel to each other-thus defining a privileged symmetry axis for the monument-and fixed in sockets carved into the bedrock (the monoliths, each weighing several tons, were extracted from a quarry on the hill, where many, unfinished, still remain). This layer belongs to the so-called PPNA (Pre-pottery

Giulio Magli

giulio.magli@polimi.it

1 Faculty of Civil Architecture, Politecnico di Milano, Piazza Leonardo da Vinci 32, 20133 Milan, Italy 


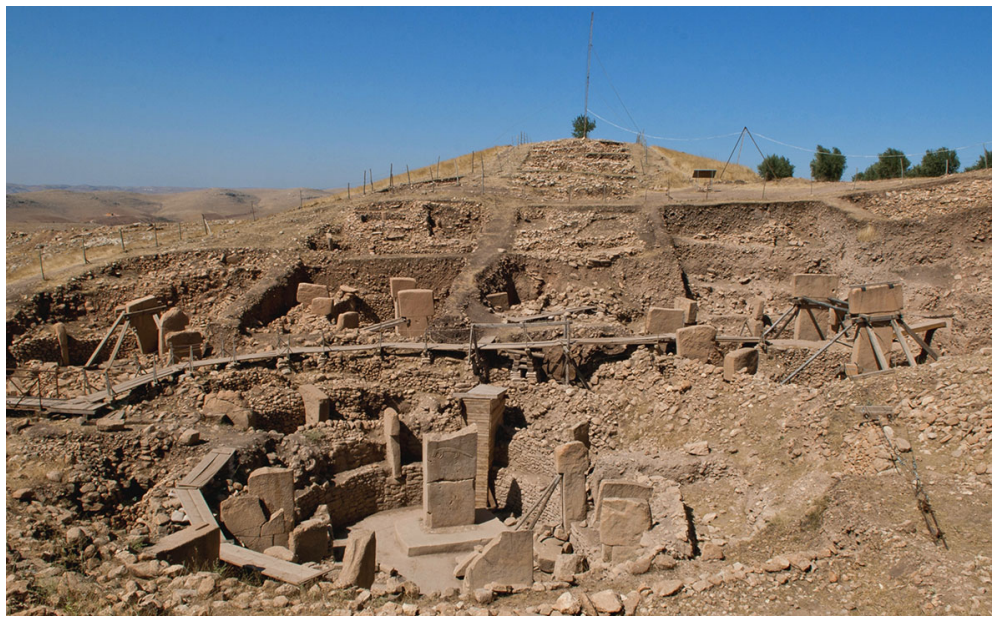

Fig. 1 Göbekli Tepe, the megalithic enclosures, view from the east. Photo: author

Neolithic A) period. Superimposed to this layer is Layer II. The Layer II monuments are smaller, almost rectangular rooms often containing two considerably smaller central pillars. These structures are archaeologically dated to the early and middle PPNB (Pre-pottery Neolithic B). The whole site was apparently frequented for a couple of millennia, and then backfilled with earth, stones and rubble before being abandoned. For reasons that are unclear, in fact, this sacred place was meticulously buried, filled in so efficiently as to preserve it as a time-capsule for posterity.

The starting point of construction activities at Göbekli is certainly in the 10th millennium BC. Establishing, however, a precise dating of the buildings and therefore also their relative chronology is difficult due to several factors, especially the fact that the datable material present in the filling is not necessarily younger than the structures. In any case, in recent years, several reliable dates have been published, a thing which will be very important in what follows.

The actual discovery of such complex architecture dating back to such a remote period of time is in itself astounding, but this is only the beginning. Most of the Göbekli pillars are in fact embellished with artistic masterpieces. These include geometric-shaped symbols, and abstract, or at any rate highly stylised, representations of humans. In particular the central pillars appear to represent anthropomorphic beings, with arms and suggestions of clothing, like loincloths. But the vast majority of the art at Göbekli is naturalistic. The reliefs depict animals, represented as single units or engaged in relatively complex scenes, and include mammals (lions, bulls, boars, foxes, gazelles), snakes and arthropods; a special role is played by birds, several species of which appear (see Rappenglueck 2009). In a later stage, as mentioned, circular enclosures gave way to rectangular ones, but the figurative art remains; for instance a pair of central pillars exhibits two magnificent carvings of lions, though with more abstract and oblong traits.

Göbekli Tepe is thus a complex place, clearly conceived of as a sacred destination and frequented by people from a wide geographical area, well before the 
"invention" of sedentarism and agriculture (Schmidt 2010). It is obvious that some sort of centralised power, or at the very least a religious influence, must have prevailed at the site, and it is patently obvious that the societies who were able to construct these first temples of humanity were also capable of investing a considerable number of man-hours in a purely idealistic, non-utilitarian project. The aim of this project were certainly symbolic, but the details are difficult to grasp. The place might have been associated with the dead and the cult of the ancestors, as the anthropomorphic pillars suggest; however, no graves have as yet been found. The presence of naturalistic depictions calls to mind cave art, but dangerous nonmammal beasts (like scorpions and snakes) are unique to Göbekli. What looks certain is that Göbekli was a centre of attraction and pilgrimage (Schmidt 2006); what then readily comes to mind is the comparison with the recent interpretations of much later megalithic architecture, especially Stonehenge and its landscape (Parker Pearson and Ramilisonina 1998). In such places, archaeoastronomy-used with the due caution which is characteristic of this discipline today, based on a strict interplay with the archaeological records - has proved to be a quite powerful tool in gaining better understanding of the symbolic world of the builders (see e.g., Ruggles 2005; Magli 2009). In what follows I will discuss an analysis of possible astronomical references at Göbekli Tepe. Contrary to existing attempts (Schoch 2012; Collins 2014; see also De Lorenzis and Orofino 2015), which have tried to associate the Göbekli circular structures with the rising/setting of conspicuous stars of the Neolithic sky (Orion to the south east or Cygnus to the north west) we propose here a different scenario, developing an idea originally put forward by the present author in a short preprint (made known in Ananthaswamy 2013). This idea is, in a nutshell, that it may have been an astronomical new and permanent phenomenon to trigger the interest of the Göbekli builders and, perhaps, to combine with their existing religion, ending up in the construction of celebratory structures. Usually indeed, astronomically unexpected phenomena-albeit quite spectacularare transient: eclipses, explosions of supernovae, appearance of comets. Instead, due to precession, a "new" star appeared in the skies of Göbekli in the tenth millennium $\mathrm{BC}$. This new object shone more and more brightly as the centuries went on, and its arc in the sky became larger, until it became the most brilliant star of all, Sirius.

Our analysis is backed up by astronomical calculations (Sect. 2), but also by a possible interpretation of one of the most elaborate reliefs at the site. In this relief, a shaman-vulture is shown "raising up" a spherical object, in a scene which might represent the Helical rising of the "new" star (Sect. 3).

\section{The orientation of the enclosures}

Astronomy is a familiar presence in the projects of megalithic sites (although its role has sometimes been exaggerated in the past). Interestingly, and although it may seem strange, there is no doubt that the ancient places which bear the most striking similarities with Göbekli Tepe are the astronomically oriented sanctuaries of Menorca, built some 8000 years later (Fig. 2). 


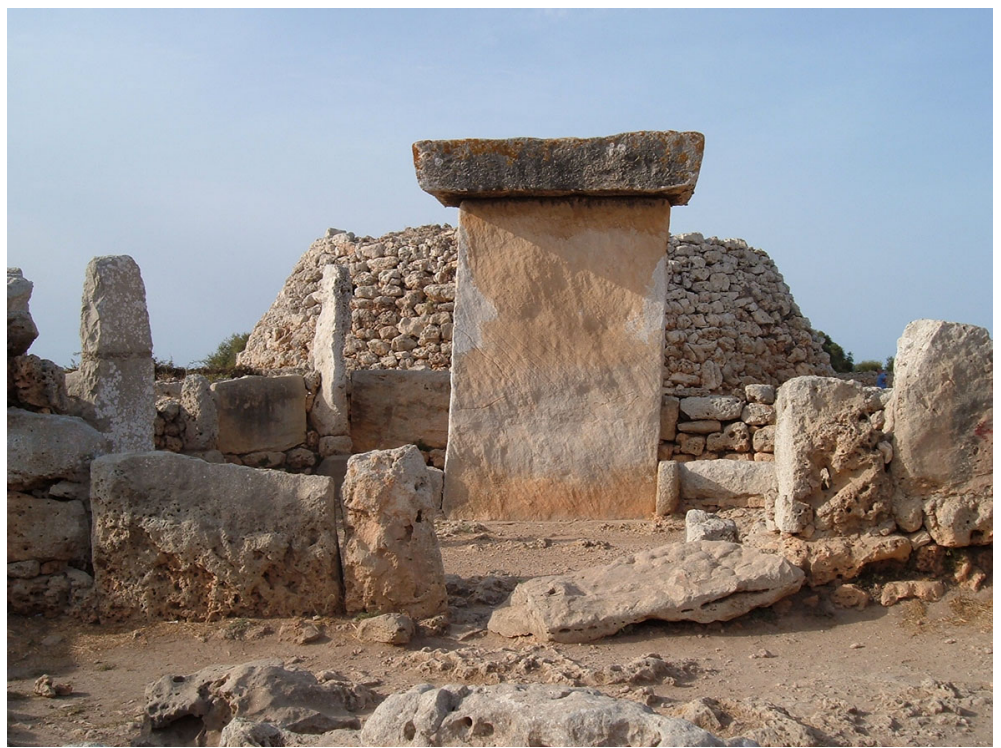

Fig. 2 Menorca. The taula at Trepuco, built around $1000 \mathrm{BC}$, some 8000 years later with respect to Göbekli Tepe. In spite of this, the similarity is impressive. Photo: author

These are oval-shaped enclosures centred on a huge, T-shaped object (commonly referred to as a Taula) composed by a huge pillar and a transverse capital. Such sanctuaries were very probably oriented to the brilliant stars of the southern sky, those of the Crux-Centaurus group, which were slowly disappearing from the Mediterranean sky due to precession (Hoskin 2001). Is it possible that a similar situation-a stellar reference slowly drifting due to precession-was present at Göbekli as well?

Astronomy is likely present at the site, since a rectangular building (Layer II) located in the area north of the enclosures is orientated to the cardinal points and might actually be the first monument ever built with such a orientation (Belmonte and García 2016). We are however interested here in the monumental, circular structures of Layer III. A possible astronomical orientation for these has been proposed in two non scholarly works. In (Schoch 2012) a possible role of the rising of the stars of Orion's belt to the south-east is proposed, while in (Collins 2014) the opposite orientation, identified as targeting the setting of Deneb and of the Cygnus constellation to the north-west, is put forward. Yet neither proposal is convincing. Orion indeed would lead to a too-high dating for the structures. Regarding a northern orientation, it is in a sense unnatural, as the enclosures are open to the south-east; orientations of temples in antiquity was usually from inside looking out, or at least, it is so for many examples, including the megalithic temples of Malta and the above-mentioned Taulas of Menorca (Hoskin 2001), as well as the Greek temples (Aveni and Romano 2000). ${ }^{1}$

\footnotetext{
${ }^{1}$ For the problem of orientation of Christian Churches, see (Belmonte and García 2015) and references therein.
} 
Table 1 Compass readings and declinations of excavated enclosures at Göbekli Tepe

\begin{tabular}{llll}
\hline Enclosure & AZ & DEC & Sirius date \\
\hline $\mathrm{D}$ & 172 & $-52^{\circ} 37^{\prime}$ & $9227 \mathrm{BC}$ \\
$\mathrm{C}$ & 165 & $-50^{\circ} 50^{\prime}$ & $8850 \mathrm{BC}$ \\
$\mathrm{B}$ & 159 & $-48^{\circ} 33^{\prime}$ & $8400 \mathrm{BC}$ \\
\hline
\end{tabular}

Consequently, we are led to inspect more carefully the southern sky at the time of construction. It then comes out that there exists another possible stellar target which has been overlooked so far. In fact, simulating the sky in the 10th millennium BC, it is possible to see that a quite spectacular phenomenon occurred at Göbekli Tepe in that period: the "birth" of a "new" star, and certainly not of an ordinary one, as it is the brightest star and the fourth most brilliant object of the sky: Sirius.

To explain this "birth" phenomenon, we must observe that precession, at the latitude of Göbekli Tepe, had brought Sirius to culminate under the horizon in the years around $15000 \mathrm{BC}$. The star therefore became invisible at that latitude many thousands of years before the construction of the first enclosures. After reaching the precessional minimum, Sirius started to come closer to the horizon and became visible again, although very low and close to due south, during the tenth millennium BC. To check if the enclosures might have been aligned with Sirius, I will consider here the three excavated ones-labelled D,C, and B-which are virtually intact, extremely similar in conception, and reasonably dated. The analysis presented below is based on compass readings of the azimuths, corrected by magnetic declination and double-checked with satellite images (estimated error of $\pm 1 / 2^{\circ}$ ); the horizon to the south-east is actually flat or slightly negative. Declinations have been calculated using the software GETDEC, kindly provided by Clive Ruggles, which takes into account refraction. To perform the simulations the program Starry Night Pro 6.0 was used (this program takes into account, besides of course precession, also the proper motion of Sirius). The results are shown in Table 1.

In Table 1, the structures have been put in a chronological order, which is coherent with what we know from archaeology. Indeed, there appears to be no doubt that structure $\mathrm{D}$ was built before structure $\mathrm{C}$, and there are few doubts that structure B is later than structure C (Schmidt 2006). The data show a series of interesting features. First of all, the azimuths decrease with increasing time, leading naturally to the idea that their construction might have (roughly) followed the precessional drift of the rising azimuth of Sirius, in a manner analogous (and opposite) to what has been proposed, for instance, for some of the Malta temples (especially Ġgantija, see Hoskin 2001), which might have been re-constructed ex novo to follow the increase of the rising azimuth of the Crux-Centaurus group. To understand if the dates (in addition to the relative chronology) provided by the Sirius hypothesis are reliable, we must resort to the specific dating of each individual structure via absolute dating methods, a field where, as mentioned in the introduction, there are several difficulties (Dietrich 2011). In any case, Structure D is currently dated 9664-9311 $\mathrm{BC}$, in good agreement with the proposed astronomical dating. One single sample 
from Structure C yielded 9261-9139 BC, while various samples from structure B are scattered in a wide window (9500-8500 BC circa) with one bone sample giving 8306-8236 BC (Dietrich and Schmidt 2011; Dietrich et al. 2013; Dietrich 2013). Thus, the astronomical hypothesis is in accordance with the archaeological data and it is not in discordance with the dating samples from the structures. In this respect, a mention about the other excavated buildings is in order. Enclosure $\mathrm{E}$ is located in a different zone of the hill (the north-west plateau) and is very poorly dated (in a window of one millennia between 9500 and 8500). Its azimuth $\left(170^{\circ}\right.$ according to existing data) would fit a declination of Sirius of $-51^{\circ} 30^{\prime}$, thus between structures D and $\mathrm{C}$, at the beginning of the ninth millennium $\mathrm{BC}$; when more accurate dating is available this enclosure might thus be used for testing the hypothesis. Enclosure A is roughly dated after enclosure $\mathrm{C}$. It is almost rectangular and it may represent the first element of the new phase (transition from the circular to the rectangular buildings); its azimuth is strongly skewed anti-clockwise with respect to those of the circular enclosures, and perhaps the architectural change also reflects a change in the interest for the celestial objects. In fact, both Enclosure A and the later Enclosure F might have been orientated towards the Moon and the Sun respectively (De Lorenzis and Orofino 2015).

A delicate point of course regards the actual visibility of Sirius. As is well known, extinction lowers the brightness of all stars near the horizon, so that a star of magnitude $\mathrm{M}$ is not visible until it has atleast $\mathrm{M}^{\circ}$ of height (the so-called Thom's law). In other words, a star of Magnitude 1 is extinguished to a magnitude $\sim 5$ (so it starts to be visible) at one degree of altitude. Thom's law is actually an empirical rule and should not be taken as a strict physical law but rather as a lower bound, as extinction phenomena can vary depending on altitude, pressure, and of course, pollution. However, there can be little doubt that the extinction coefficient was much lower than today in the ancient past (the main contribution to it having been made by the Industrial Revolution, which started massive pollution of the low atmosphere) and that Thom's rule gives us a reasonable working framework. Since Sirius is a negative magnitude star $(\mathrm{M}=-1.46)$, it follows that it was visible just above the horizon, as bright as a star of magnitude $\sim 4$, that is, not a very conspicuous object (to fix ideas, it was more or less as bright as our pole star Polaris). However, the presence of such a new star could have been easily noticed in the clear sky of those times. Further, once noticed, the "guest star" not only did not disappear after a few days - as a nova, or a comet — but started to culminate higher and therefore to become brighter with the passing of the years, up to definitively occupying the place which was reserved to her, namely, that of the most brilliant star of the sky as seen from the earth.

\section{Possible references to the heliacal rising of Sirius in the iconography}

Due to a curious coincidence, the heliacal rising of the "new star" occurred very close to the summer solstice. To fix ideas, I will consider here the year 9000 BC. In the proleptic Julian calendar, the summer solstice occurred on 27 August. On this day, Sirius was rising when the sun was at an altitude of $-15^{\circ}$, so the star was 


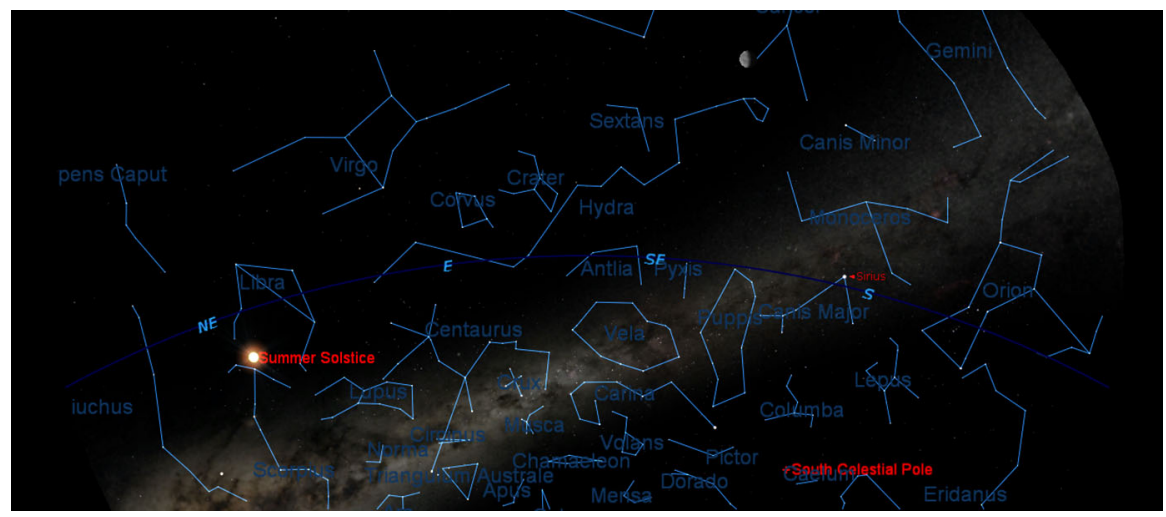

Fig. 3 Göbekli Tepe, 9000 BC. Rising of Sirius at dawn of Midsummer. The sun-below the outlined horizon-was located just above Scorpio. Image: author, produced with Starry Night Pro 6

certainly visible for a few minutes just before sunrise. It is very difficult to define a precise day of the heliacal rising, as the first visibility of a star depends on many circumstances (e.g., the presence or absence of the Moon, the skill of the observer, and so on), so Sirius might have been barely visible just before dawn a few days before as well (Fig. 3).

All in all, we can safely consider the phenomenon to occur at least in rough concomitance with the summer solstice. I would thus propose the possibility that the image of the "birth" of Sirius in connection with the sun might help in interpreting one of the most "mysterious" images present in the iconography at the site-to be exact, that found on one of the most elaborate of the pillars, Megalith 43 of structure D (Fig. 4).

The decoration of this pillar has many similarities to that of the (of course much later) Babylonian boundary stelae, called kudurru, which contained detailed references to the sky. In particular, these stelae contained a register (one of the bands into which the stelae are divided) with "box" altars devoted to the gods of the sky that are very similar to the "bags" appearing in the upper register of the Göbekli pillar. Several constellations were depicted in the lowermost register of the kudurrus, again in a way similar to the Göbekli pillar if the figures there-a scorpion, a goose, a fox and a headless ithyphallic man-are taken to be constellations. Besides this analogy, what is really impressive is the scene in the middle register of the Göbekli Pillar. In front of a rectilinear band of small squares and v-shaped motifs we find a vulture, which seems to be raising a circular object, and two wading birds, the lower one perhaps a newborn (a serpent or phallic symbol, and two bone-shaped or H-shaped carvings complete the scene).

There is no doubt that the vulture has human-like features: the expression resembles a smile and the way it stretches its wings is unnatural for a bird but would be very natural for a man wearing fake wings. So it is likely that the image depicts a therianthrope (a hybrid human-animal creature) or, more simply, a shaman wearing a vulture costume. Vultures are connected with the dead and appear together with headless human bodies in the art of Catal Huyuk (6500 BC), which is chronologically 
Fig. 4 Göbekli Tepe. The carvings on Pillar 43. Photo: author

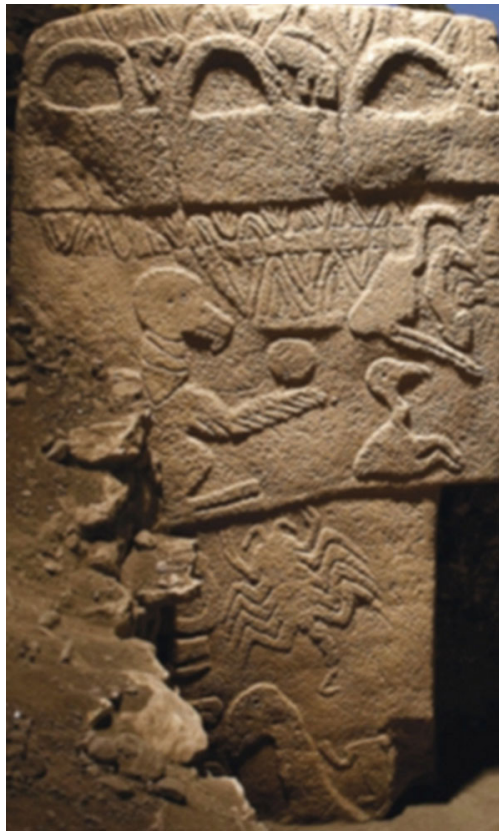

not so remote from Göbekli. However, birds, and the vulture in particular, have also been repeatedly associated with the sun in many cultures (an obvious case being ancient Egypt) (Rappenglueck 2009). For this reason, the scene might represent the "birth" of Sirius, borne aloft by the sun. An hint that the day may be the summer solstice comes from the fact that at the end of the tenth millennium BC the summer solstice was on the point of leaving Scorpio and the rising sun was therefore just above the head of the animal. As a consequence of course Scorpio was invisible at the solstice, being just below the horizon, under the sun: in a sense Scorpio was in the realm of the dead, as indeed it is on the stela, along with a decapitated man, in the register beneath the main scene. It goes without saying, however, that we cannot be sure that the ancient builders recognized the constellation Scorpio in the sky as the Babylonians (and consequently the Greeks, the Romans, and us) did much later, so this proposal must remain at the level of a suggestion.

\section{Discussion}

To conclude, the above arguments suggest that the building of the structures of Göbekli Tepe were related in some way to the appearance of a brilliant "guest" star in the sky: Sirius. This would imply that the birth of monumental architecture was related to the observation of the celestial cycles since the very beginning. Of course, although fascinating, such an hypothesis must be taken with due caution, as the author is well aware that this it is still in the speculative realm. However, there are 
concrete hopes of putting the idea to the test in the near future. First of all, new and more precise dates for the relative chronology of the existing structures will probably be available, allowing us to situate Enclosure $\mathrm{E}$ in a more accurate time scale, as well as to fine-tune the dating of the other structures. Further-hopefullynew enclosures will be brought to light: actually, at the moment of writing, a new structure (Enclosure H) is under active excavation (Dietrich et al. 2014).

\section{References}

Ananthaswamy, Anil. 2013 Stone Age temple tracked the dog star. New Scientist 2930, 17 August 2013. Aveni, Anthony F. and Giulio Romano. 2000. Temple Orientations in Magna Graecia and Sicily. Journal for the History of Astronomy 31: 51-57.

Belmonte, Juan Antonio and César González-García. 2016. Astronomy, Landscape and Power in Eastern Anatolia. SEAC2010 on Astronomy and Power, How worlds are structured, Michael Rappenglueck, ed. BAR Int. Ser. (in press).

Belmonte, Juan Antonio and César González-García. 2015. The Orientation of Pre-Romanesque Churches in the Iberian Peninsula. Nexus Network Journal 17(2): 353-377.

Collins, Andrew. 2014. Göbekli Tepe: Genesis of the Gods. Bear \& Company, London.

De Lorenzis, Alessandro and Vincenzo Orofino. 2015. New Possible Astronomic Alignments at the Megalithic Site of Göbekli Tepe. Archaeological Discovery 3, 40-50.

Dietrich O (2013) Göbekli Tepe. Ex Oriente. PPND - The Platform for Neolithic Radiocarbon Dates. http://www.exoriente.org/associated_projects/ppnd_site.php?s=25. Accessed 16/10/2015.

Dietrich, Oliver, Çiğdem Köksal-Schmidt, Jens Notroff, and Klaus Schmidt. 2013. Establishing a Radiocarbon Sequence for Göbekli Tepe. State of Research and New Data. Neo-Lithics 1: 36-47.

Dietrich, Oliver and Klaus Schmidt. 2011. A Radiocarbon Date from the Wall Plaster of Enclosure D of Göbekli Tepe. Neo-Lithics 2: 82-83.

Dietrich, Oliver. 2011. Radiocarbon dating the first temples of mankind. Comments on 14C-Dates from Göbekli Tepe. Zeitschrift für Orient-Archäologie 4: 12-25.

Dietrich O, Jens N, Klaus S (2014). Recent Research 2013/14: Insights into a new Enclosure at Göbekli Tepe. John Templeton Foundation - Newsletter, September 2014: 5-6.

Hoskin, Michael. 2001. Tombs, temples and their orientations. Bognor Regis: Ocarina books.

Magli, Giulio. 2009. Mysteries and Discoveries of Archaeoastronomy. New York: Springer.

Parker Pearson, Mike and Ramilisonina. 1998. Stonehenge for the ancestors: The stones pass on the message. Antiquity 72: 308-326.

Rappenglueck M (2009) Heavenly Messengers: The Role of Birds in the Cosmographies and the Cosmovisions of Ancient Cultures. In: J. A. Rubino-Martın, J. A. Belmonte, F. Prada and A. Alberdi, eds., Cosmology across cultures ASP Conference Series 409: 145-150.

Ruggles, Clive L. N. 2005. Ancient Astronomy: An Encyclopedia of Cosmologies and Myth. London: ABC-CLIO.

Schmidt, Klaus. 1998. Beyond Daily Bread: Evidence of Early Neolithic Ritual from Göbekli Tepe. NeoLithics 2: 1-5.

Schmidt, Klaus. 2001. Göbekli Tepe, Southeastern Turkey. A preliminary report on the 1995-1999 excavations. Paléorient 26(1): 45-54.

Schmidt K (2006) Sie bauten die ersten Tempel. Das rätselhafte Heiligtum der Steinzeitjäger. Die archäologische Entdeckung am Göbekli Tepe. Munich: C.H. Beck.

Schmidt K (2010) Göbekli Tepe: the Stone Age Sanctuaries. New result of ongoing excavations with a special focus on sculptures and high reliefs. In M. Budja, ed., 17th Neolithic Studies. Documenta Praehistorica 17: 239-256.

Schoch, Robert. 2012. Forgotten Civilization: The Role of Solar Outbursts in Our Past and Future. New York: Inner Traditions. 
Giulio Magli is an archaeoastronomer who works primarily on the relationship between the architecture of ancient cultures and the sky. After receiving his Ph.D. in Mathematical Physics at the University of Milan, he initially conducted research in Relativistic Astrophysics but gradually developed a special interest in the relationship between architecture, landscape, and the mathematical/astronomical lore of ancient cultures, especially among the Ancient Egyptians, the Incas and in the Mediterranean. He became full professor of Mathematical Physics at the Politecnico di Milano in 2005, and since 2009 he has taught the only official course on Archaeoastronomy ever established in Italy. He has been one of the authors of the UNESCO document on Astronomy and Cultural Heritage and is appointed director of the FDS Laboratory for the Communication of Science. His books include Mysteries and Discoveries of Archaeoastronomy (Springer 2009) Architecture, Astronomy and Sacred Landscape in Ancient Egypt (Cambridge University Press 2013) and Archaeoastronomy. Introduction to the science of stars and stones (Springer 2015). 